\title{
Developmental trends in different types of spontaneous false memories: implications for the legal field
}

Citation for published version (APA):

Otgaar, H., Howe, M. L., Peters, M., Sauerland, M., \& Raymaekers, L. (2013). Developmental trends in different types of spontaneous false memories: implications for the legal field. Behavioral Sciences \& the Law, 31(5), 666-682. https://doi.org/10.1002/bsl.2076

Document status and date:

Published: 01/09/2013

DOI:

10.1002/bsl.2076

Document Version:

Publisher's PDF, also known as Version of record

Document license:

Taverne

Please check the document version of this publication:

- A submitted manuscript is the version of the article upon submission and before peer-review. There can be important differences between the submitted version and the official published version of record.

People interested in the research are advised to contact the author for the final version of the publication, or visit the DOI to the publisher's website.

- The final author version and the galley proof are versions of the publication after peer review.

- The final published version features the final layout of the paper including the volume, issue and page numbers.

Link to publication

\footnotetext{
General rights rights.

- You may freely distribute the URL identifying the publication in the public portal. please follow below link for the End User Agreement:

www.umlib.nl/taverne-license

Take down policy

If you believe that this document breaches copyright please contact us at:

repository@maastrichtuniversity.nl

providing details and we will investigate your claim.
}

Copyright and moral rights for the publications made accessible in the public portal are retained by the authors and/or other copyright owners and it is a condition of accessing publications that users recognise and abide by the legal requirements associated with these

- Users may download and print one copy of any publication from the public portal for the purpose of private study or research.

- You may not further distribute the material or use it for any profit-making activity or commercial gain

If the publication is distributed under the terms of Article 25fa of the Dutch Copyright Act, indicated by the "Taverne" license above, 


\title{
Developmental Trends in Different Types of Spontaneous False Memories: Implications for the Legal Field
}

\author{
Henry Otgaar, Ph.D. ${ }^{\dagger} *$, Mark L. Howe ${ }^{\ddagger}$, Maarten Peters ${ }^{\S}$, \\ Melanie Sauerland, Ph.D. ${ }^{\S}$ and Linsey Raymaekers ${ }^{\S}$
}

In an emerging area of memory research, it is becoming apparent that one particular type of false memory, called spontaneous false memory, follows a developmental trajectory that is the opposite of what is commonly assumed in false memory research that is, spontaneous false memories are more likely to occur in adults than in children. The present study focused on developmental trends of different types of spontaneous false memories. Specifically, in the current study, 6-8 year-olds, 10-12 year-olds, and adults were presented with two methods to induce spontaneous false memories: (i) semantically related word lists that are commonly used to evoke spontaneous false memories [i.e, Deese-Roediger-McDermott (DRM) paradigm]; and (ii) a video in which related details were not shown but were presented during a recognition task. The results showed that children were more likely to form false memories than adults in the video false memory paradigm, whereas DRM false memories were more evident in adults than in children. Furthermore, we found that on a general level, DRM false memories were positively related to video spontaneous false memories. We explain that stimuli that contain obvious themes attenuate or even reverse developmental trends in spontaneous false memories. Copyright (C) 2013 John Wiley \& Sons, Ltd.

To be able to successfully survive in our environment, we have to be confident our memories can be trusted. Although this trust is often legitimized, errors in our memory occasionally surface. Such false memories can be quite innocuous when they occur in daily life (e.g., misremembering that you bought red wine when in fact you bought white wine), yet can be egregious when they appear in legal proceedings of, for example, child sexual abuse. In most of these cases, legal professionals are interested in the reliability of memories and whether such memories can be contested (Brainerd, Reyna, \& Ceci, 2008). Importantly, in legal cases, memory recollections are often the determining evidence factor in deciding whether a suspect should be convicted. It is therefore not surprising that memory scholars have been interested in the fallibility of memory (Loftus, 2005).

\footnotetext{
*Correspondence to: Henry Otgaar, Ph.D. Clinical Psychological Science, Faculty of Psychology and Neuroscience, Maastricht University, PO Box 616, 6200 MD, Maastricht, the Netherlands. E-mail: Henry.Otgaar@ maastrichtuniversity.nl

${ }^{\dagger}$ Clinical Psychological Science, Faculty of Psychology and Neuroscience, Maastricht University, PO Box 616, 6200 MD, Maastricht, the Netherlands

${ }^{\ddagger}$ Department of Psychology, City University, London, UK

${ }^{\S}$ Maastricht University, The Netherlands
} 
Previous studies have painted quite a consistent picture with respect to the malleability of memory; that is, false memories that are the result of suggestive pressure are easily elicited and are more likely to be induced in children than in adults (Brainerd et al., 2008). Suggestion-based false memories are generally studied using two false memory paradigms: misinformation and implantation (e.g., Otgaar, Candel, \& Merckelbach, 2008; Otgaar, Verschuere, Meijer \& van Oorsouw, 2012). In the misinformation paradigm, participants are presented with stimuli (e.g., video of a theft) or are exposed to a live event. After this, participants are given suggestive questions (e.g., "The perpetrator had a pistol, didn't he?"). These suggestive manipulations cause a significant minority of participants to fall prey to the suggestion and develop false memories for the details mentioned but not actually seen or experienced (Loftus, 2005; Otgaar, Candel, Smeets \& Merckelbach, 2010; Pezdek \& Roe, 1997; Sutherland \& Hayne, 2001).

Other studies focus on the implantation of false memories for entire events (e.g., Ceci \& Huffman, 1997; Loftus \& Pickrell, 1995; Otgaar, Candel, Scoboria \& Merckelbach, 2010; Otgaar et al., 2008). In these implantation paradigms, participants receive narratives about events in their childhood allegedly obtained from their parents but which did not actually happen. However, one of these narratives refers to a nonexperienced event manufactured by the experimenter (e.g., a hot air balloon ride). Participants are instructed to report everything they can recollect about the events. Interestingly, the use of false narratives leads to a significant proportion of participants erroneously remembering the fictitious event.

The development of suggestion-based false memories has often been explicated in terms of source monitoring errors. According to the source monitoring framework (Johnson, Hashtroudi, \& Lindsay, 1993), images, thoughts, and feelings that are experienced as memories are attributed to specific sources. When these attributions err, images, thought, and feelings are assigned to incorrect sources [attribution of a recollection to an internal source (e.g., memory of the misleading information) while it should be to an external source (e.g., the misleading question that was asked)]. It is this misattribution that can result in the creation of false memories. Because the ability to monitor the sources of recollections advances significantly from childhood to adulthood (e.g., Lindsay, Johnson, \& Kwon, 1991), false memories are less likely to occur as children get older. This idea fits nicely with studies showing there is an age-related decrease in suggestion-based false memories (e.g., Otgaar, Candel, Merckelbach, \& Wade, 2009). The age-related decrease in suggestibility has also been explained in terms of coerced social influence effects (Ceci \& Bruck, 1993); that is, children are more likely to be persuaded by authoritative persons (e.g., police officers, experimenters, adults) than adults and are therefore more likely to accept suggestions than adults.

Recently, however, memory researchers have become increasingly interested in the examination of spontaneous false memories (Brainerd et al., 2008; Otgaar \& Candel, 2011). Spontaneous false memories are false memories that arise without external suggestive pressure and develop because of internal processes such as, for example, spreading activation (Howe, Wimmer, Gagnon, \& Plumpton, 2009). What makes this type of false memory so appealing to study is that their development has been mainly predicted by theoretical accounts such as Fuzzy-trace Theory (FTT; Brainerd et al., 2008) and Associative-activation Theory (AAT; Howe et al., 2009; Otgaar, Howe, Peters, Smeets \& Moritz, 2012). Furthermore, these theoretical accounts have predicted that in certain situations, the traditional developmental view of false memories 
(i.e., age-related decrease in false memory) is untenable. According to FTT and AAT, false memories that arise spontaneously should show an opposite developmental trend, with children being less vulnerable to the formation of false memories than adults.

To see how FTT and AAT explain the development of false memories, it is important to understand the communalities and differences between these theories. FTT stipulates that two traces are stored when people experience an event (Brainerd et al., 2008). 'Verbatim traces' are involved in the storage of item-specific and surface details of an event, whereas 'gist traces' extract the underlying semantics or meaning of an event. So gist traces capture the underlying associations and, more specifically, the underlying meaning of an event. Since verbatim traces fade more rapidly than gist traces, people rely more on gist over time. Furthermore, research shows that adults are better at extracting the gist of experiences than children. According to FTT, false memories are built upon reliance on gist traces. As a result, because adults are better able to get the gist of an experience than children, FTT predicts that false memories are more pronounced in adults than in children, an effect also known as developmental reversal (Brainerd et al., 2008).

The basic tenet of AAT is that false memories are the result of associative activation between interconnected nodes in one's knowledge base (Howe et al., 2009; Otgaar, Howe, et al., 2012). Furthermore, AAT stipulates that the associative activation between interconnected nodes increases in strength and automaticity as a function of age, with adults displaying stronger automatic connections between elements than children. These increases co-occur with increases in false memories from childhood to adulthood. So, as with FTT, AAT predicts that false memories should increase with age when people rely on associative activation processes in their knowledge base. Indeed, recent evidence even shows that suggestion-based false memories increase with age when children and adults rely on associative activation processes (Otgaar, Howe, et al., 2012). Although both FTT and AAT predict that false memories increase with advancing age during childhood, FTT and AAT differ on a number of levels.

First of all, FTT is a dual-process theory, while AAT can be considered a singleprocess theory. Although there is significant merit in adopting a dual-process view when studying certain spheres in cognitive development (e.g., memory, emotion, decision-making; Reyna \& Brainerd, 2011), dual-process theories are not without criticism. For example, studies show that for certain dual-process theories, separate components of these theories are highly interrelated, suggesting that a single-process view could better account for findings (e.g., Pratte \& Rouder, 2011). Secondly, with respect to false memory, dual-process theories such as FTT stress that people first extract the gist of an experience before other related elements are activated in a network, while AAT assumes that activation spreads immediately through an interrelated network of nodes (Howe et al., 2009). Thirdly, FTT does not contain any assumptions about automaticity while AAT does. Hence, AAT can make certain predictions (e.g., divided attention interferes with the automaticity of false memories; Otgaar, Peters \& Howe, 2012) that FTT is unable to.

Whatever interpretation is more parsimonious and more able to explain the breadth of data concerning false memory formation, both FTT and AAT are influential theories with regard to the development of spontaneous false memories. A customary method to elicit spontaneous false memories is the Deese-Roediger-McDermott (DRM; Deese, 1959; Roediger \& McDermott, 1995) paradigm. In this paradigm, participants receive word lists consisting of semantically related words (e.g., tears, weep, sorrow) that are 
associatively related to a critical, non-presented lure word (i.e., cry). Recall and recognition tests show that a significant minority of participants falsely remember the critical lure.

Although the DRM illusion has been criticized for a lack of ecological validity (e.g., DePrince, Allard, Oh, \& Freyd, 2004), recent studies have revealed that this position is untenable. Besides the robustness of the DRM false memory illusion, DRM false memories have been shown to relate to autobiographical memories (Gallo, 2010; but see also Otgaar \& Candel, 2011). Also, word lists have been shown to evoke emotional reactions that parallel emotional situations in daily life (Rubin \& Talarico, 2009).

Another often-posed critique is the issue of whether spontaneous false memories, such as the DRM illusions, share similar mechanisms to suggestion-based false memories (Pezdek \& Lam, 2007; Wade et al., 2007). There are studies showing that certain distinctive populations (e.g., people with therapy-induced recovered memories of abuse, past lives, alien abduction; e.g., Clancy, McNally, Schachter, Lenzenweger, \& Pitman, 2002; Geraerts et al., 2009; Meyersburg, Bogdan, Gallo, \& McNally, 2009) have a heightened propensity to the formation of spontaneous false memories. The main conundrum of these studies is that the "false" autobiographical memories of, for example, sexual abuse were not triggered under strict experimental control, thereby opening the door for potential confounding variables (e.g., presence of psychological disorders). Studies that have compared experimentally evoked suggestion-based false memories with spontaneous false memories have found mixed findings. Some studies found no relation between spontaneous and suggestion-based false memories (e.g., Otgaar \& Candel, 2011; Wilkinson \& Hyman, 1998), while others did find a positive relation (Otgaar et al., 2012; Qin, Ogle, \& Goodman, 2008).

It must be stressed that extant data on the development of other types of spontaneous false memories are scarce (e.g., spontaneous false memories that are evoked by means of other paradigms). So, although studies are revealing that the development of the DRM illusions runs counter to the development of suggestion-based false memories that arise out of social influences, it remains to be seen whether this developmental trend also holds for other types of spontaneous false memories. Examining this issue is vital, as it would extend our insight into the mechanisms behind the development of spontaneous false memories. That is, if it is true that spontaneous false memories are elicited by means of reliance on gist processing or associative activation, then similar developmental trends should be expected to those found with the DRM illusion. Furthermore, developmental trends in spontaneous false memories should vary in predictable ways according to the tenets of FTT and AAT (see later).

Thus, the purpose of the present study is to examine development trends in another type of spontaneous false memory than DRM illusion. Specifically, we will examine how children (6-8 year-olds and 10-12 year-olds) and adults react when they receive a video false memory paradigm that elicits robust levels of spontaneous false memories (Peters, Hauschildt, Moritz, \& Jelinek, in press). We decided to include videos as a means to induce spontaneous false memories for the following reasons: (1) in order to test whether an age-related increase in false memories also occurs when more reallife events are experienced, the inclusion of videos might be an ideal strategy; and (2) compared with word lists, it is likely that it is easier to grasp the underlying theme (i.e., what the video is about) of a video. As we will show later, themes are likely to affect the creation of spontaneous false memories. So, participants are presented with videos (e.g., a fight) in which certain critical elements are removed. Then, they are 
presented with a recognition task. These age groups were selected because previous studies have shown that false memory propensity differs significantly between these groups (Brainerd et al., 2008). A secondary aim of this study is to assess how these video false memories are related to the DRM illusion. Thus, in the present study, participants will be presented with both the video false memory paradigm and the DRM paradigm.

What might be predicted with respect to developmental trends using this video false memory paradigm? Based on FTT, one might expect that children are less likely to grasp the gist of the videos than adults and thus are less susceptible to developing false memories than adults, thereby resulting in a developmental reversal effect. Although one might assume that, according to AAT, children will have fewer opportunities to associatively activate related, yet non-presented items about the video relative to adults, leading to a development reversal effect, studies have shown that when experiences have an obvious underlying theme, developmental trends can be attenuated or even reversed (e.g., Howe \& Wilkinson, 2011). The explanation for this is that AAT postulates that theme nodes can lead to direct and automatic access, which can benefit children more than adults, whose associative activation skills are already well developed. As a result, such stimulus material can place children's associative activation at a level that is equal to or even higher than that of adults, thereby shifting standard developmental trends in spontaneous false memories.

Indeed, there are studies that have confirmed that experiences with obvious underlying themes can attenuate and sometimes reverse developmental trends in spontaneous false memories. These studies have used material other than DRM word lists to foster spontaneous false memory production and in which the underlying theme and structure are more easily identified than DRM word lists. So, to provide certain examples, some researchers have used story contexts in which DRM stimuli were included to bias children's and adults' false memory production (Dewhurst, Pursglove, \& Lewis, 2007; Howe \& Wilkinson, 2011; Swannell \& Dewhurst, in press). Dewhurst et al. found that 5-year-olds evinced higher spontaneous false memory levels than older children (8- and 11-year-olds) when story contexts were used as false memory stimuli. This finding has been broadly replicated by others (Howe \& Wilkinson, 2011; Swannell \& Dewhurst, in press) who showed that stimulus materials such as stories increase automatic processing, especially for young children, thereby weakening or flipping developmental patterns in spontaneous false memories.

We have recently conducted a series of experiments showing that the use of a visual false memory paradigm with scene-like, visual pictures (e.g., picture of a beach) also reversed the standard developmental spontaneous false memory trend (Otgaar, Howe, et al., 2012). That is, across three experiments we found that children developed higher levels of spontaneous false memories when presented with these visual scenes than adults who received the same stimuli. Our interpretation of this finding was that, like the story contexts, the visual scenes permitted faster and more automatic access to theme nodes, thereby resulting in even higher spontaneous false memory levels for children than for adults.

Extending this line of reasoning, one might assume that being exposed to videos will also result in a better identification of the underlying theme of the videos than when word lists are used. So, based on AAT's view of theme nodes, we would expect that when using this video false memory paradigm, children will have spontaneous false memory levels that are equal to or higher than those of adults. Yet, for the DRM lists, 
we would expect a developmental reversal effect. Furthermore, if similar mechanisms, such as associative activation, play a significant role in the development of false memories, our expectation is that there will be a positive relationship between video and DRM false memories.

Researchers have recently also resorted to the inclusion of more forensically relevant material to evoke spontaneous false memories. The reason for using such material is to better mimic real-life situations in which false memories can have devastating effects, such as, for example, criminal trials of sexual abuse. So, recent studies have included emotionally negative and arousing DRM word lists to stimulate false memory production (e.g., Brainerd, Holliday, Reyna, Yang, \& Toglia, 2010; Goodman et al., 2011; Howe, Candel, Otgaar, Malone, \& Wimmer, 2010). In general, these studies have found that although recall measures show that neutral false memories are more likely to develop than negative false memories, the latter are more easily falsely recognized than the former - a finding that has also been demonstrated with suggestion-based false memories (e.g., Otgaar et al., 2008; Porter, Taylor, \& ten Brinke, 2008). This finding has been explained in terms of better gist extraction (Brainerd et al., 2010) or more rapidly spreading activation through related nodes in an individual's knowledge base (Howe et al., 2009) for emotionally negative and arousing material than for neutral material. Hence, in the present experiment, we presented 6-8 year-olds, 10-12 year-olds, and young adults with neutral, emotionally negative and positive videos to engender spontaneous false memories. Furthermore, participants received neutral and negative DRM lists. Our prediction was that for both false memory paradigms (video and DRM), false memories would be more easily recognized for the negative than for the neutral material.

\section{METHOD}

\section{Participants}

A total of 90 participants were included in the current experiment with $306-8$ year-olds (mean age $=6.77, \mathrm{SD}=0.50 ; 12$ boys), $3010-12$ year-olds (mean age $=10.97$, $\mathrm{SD}=0.41 ; 12$ boys), and 30 young adults (mean age $=20.97, \mathrm{SD}=1.99 ; 10$ men). Children were recruited from elementary schools from the south of the Netherlands. Parents provided written consent for their children. All children were awarded with a small present for their participation. Adults were students from the Faculty of Psychology and Neuroscience, Maastricht University, and received course credits or financial compensation $(€ 7.50)$ for their involvement. The study was approved by the standing ethical committee of the Faculty of Psychology and Neuroscience, Maastricht University.

\section{Materials}

\section{Video False Memory Paradigm}

We used a video false memory paradigm constructed by Peters et al. (in press) which is built around the principles of the DRM paradigm. Specifically, in the current study, participants were presented with three videos that differed with regard to valence 
(i.e., emotional aspect of an event: negative, neutral, or positive). Each video lasted for about 1.5 minutes. Themes and complexity of the videos were based upon the following considerations: (1) universally familiar from personal experience (human daily-life interactions); (2) easy to identify as theme; (3) detailed dynamic setting; and (4) suitable for the emotional content. The negative video was about a street fight, the neutral video referred to an electrician carrying out several tasks in a house, and the positive video depicted a child's birthday party.

To test whether children and adults experienced the videos as emotionally or not, we conducted a pilot study with five 7 -year-olds (mean age $=7, \mathrm{SD}=0$ ), five $11-12$ year-olds (mean age $=11.20, \mathrm{SD}=0.45$ ), and 10 young adults (mean age $=22.70, \mathrm{SD}=4.57$ ). They received the three videos in a random order and had to provide valence ratings on a five-point Likert scale ( $1=$ very negative, $3=$ neutral, $5=$ very positive) after watching each video. A 3 (age: 7-year-olds, 11-12 year-olds, adults) $\times 3$ (valence: negative, neutral, positive) repeated-measures ANOVA yielded a significant main effect of valence $\left[F(2,34)=33.91, p<0.001, \eta_{\text {partial }}^{2}=0.67\right)$. Post hoc tests using Bonferroni correction revealed that the three videos differed significantly from each other [all $p$-values $<0.01 ; M_{\text {negative }}=1.70, \mathrm{SD}=1.13 ; M_{\text {neutral }}=3.00, \mathrm{SD}=0.56$; $M_{\text {positive }}=3.75, \mathrm{SD}=0.44$; see Peters et al. (in press) for similar findings with adult participants]. All other effects did not meet statistical significance (all $F$-values $<1$, all $p$-values $>0.05$ ).

The recognition task was composed of 72 items. Specifically, it consisted of 12 "old" presented items for each video (36 in total) with a corresponding contextual cue from the specific video. Furthermore, 12 "new", non-presented items for each video were included (36 in total) with three new, unrelated items (e.g., fish in the street fight video) and nine critical, related items (e.g., police writing on a motor car in the street fight video). These items were presented in a pseudo-random order. Importantly, the critical items were more strongly associatively related to the presented items than to the unrelated non-presented items (Peters et al., in press).

\section{DRM Paradigm}

We used five neutral (bread, window, sweet, smoke, feet) and five negative (murder, pain, punishment, death, cry) DRM word lists, with each list containing 10 words. The effectiveness of these lists in eliciting spontaneous false memories has already been demonstrated in previous research (Howe et al., 2010; Otgaar \& Candel, 2011; Otgaar et al., 2012b). List items were chosen from the Dutch word association norms (Van Loon-Vervoorn \& Van Bekkum, 1991) and were presented in order of backward associative strength, from strongest to weakest, in line with Howe et al. (2010) and Otgaar and Candel (2011). With the assistance of the CELEX lexical database (Baayen, Piepenbrock, \& Gulikers, 1995), we made sure that the mean word frequency of the neutral and emotional critical lures did not differ $[t(8)=0.22$, ns]. The mean backward associative strength between the neutral list items and their critical lure and the mean backward associative strength between the negative list items and their critical lures did not differ either $[t(8)=1.69, \mathrm{~ns}]$. We presented the lists in a fixed random order. Words were presented in an auditory manner via a computer. The 78 -word recognition task was composed of 40 "old" presented words (four from each list), 10 critical lures, 10 associatively, related non-presented words, and 18 unrelated nonpresented words. 


\section{Design and Procedure}

We used a 3 (age: 6-8 year-olds, 10-12 year-olds, adults) $\times 3$ (valence: negative, neutral, positive) split-plot design with the latter being a within-subjects variable. The videos were presented in a random order. The order of the presentation of DRM word lists and the videos was counterbalanced.

At the start of the experiment, participants were informed that they participated in a memory experiment. When participants received the videos, they were instructed to pay close attention to the videos. After the presentation of the third video, participants received the recognition task of the videos. They were asked to indicate whether they had seen a particular item on a video by using the following sentence for each item: "Did you see [item] on the video of the [name of the video]?" The recognition task was presented by the experimenter. When participants were presented with the DRM word lists, they were told to try to memorize the words as well as possible. After this, the recognition task was presented by the experimenter. At the end of the experiment, each participant was debriefed.

\section{RESULTS}

\section{Video False Memory Paradigm}

\section{True Memory}

We conducted a 3 (age: 6-8 year-olds, 10-12 year-olds, adults) $\times 3$ (valence: negative, neutral, positive) repeated-measures ANOVA on the proportion of true recognition. No significant interaction emerged $(F<1, p>0.05)$. We did, however, find a significant main effect of age $\left(F(2,87)=5.37, p<0.01, \eta_{\text {partial }}^{2}=0.11\right)$. Post hoc Bonferroni analyses revealed that adults and the older children had significantly higher recognition levels than the younger children ( $p$-values $<0.05$; see Table 1 ). However, adults and older children did not differ in their true recognition levels. A significant main effect of valence was also detected $\left(F(2,174)=10.38, p<0.001, \eta_{\text {partial }}^{2}=0.11\right)$, with post hoc Bonferroni tests revealing the following. Participants had significantly higher true recognition levels for the positive and neutral videos than for the negative video ( $p$-values $<0.05)$. No differences were found between true recognition levels of the positive and neutral videos $(p>0.05)$.

\section{False Memory}

A repeated-measures ANOVA on the proportion of false recognition for the critical items yielded the following results. No significant interaction emerged. We found a significant main effect of age $\left[F(2,87)=13.72, p<0.001, \eta_{\text {partial }}^{2}=0.24\right.$; see Table 1$]$. Additional post hoc tests showed that the older and younger children were more likely to develop false memories than the adult sample $(p$-values $<0.05)$. The two child samples did not, however, differ significantly. Our analysis also revealed a significant valence effect $\left[F(2,174)=5.67, p<0.01, \eta_{\text {partial }}^{2}=0.06\right]$ with Bonferroni tests showing that neutral $(p<0.05)$ and positive false memories (borderline significant; $p=0.06$ ) were more likely to occur than negative false memories. Participants did not differ in 


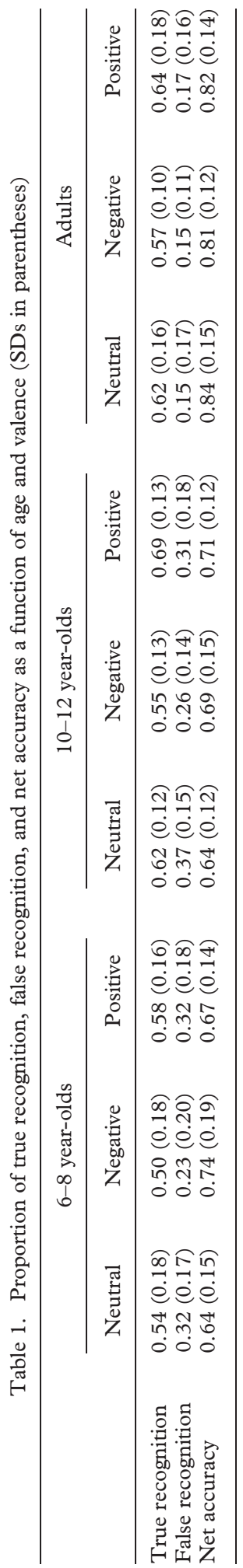


their susceptibility to false memories for the neutral or positive videos $(p=1.00)$. With respect to the unrelated items, no significant effects emerged (all $F$-values $<1$, $p$-values $>0.05$ ).

\section{Net Accuracy}

To examine how children and adults differed in their net accuracy scores (true recognition/true + false recognition), we conducted a repeated-measures ANOVA on the accuracy scores (see Otgaar \& Smeets, 2010). Because of a violation of sphericity (i.e., assumption that variances of the differences between data from the same participants are equivalent), Greenhouse-Geisser correction analyses revealed a significant age $\times$ valence interaction $\left[F(3.59,156.32)=2.80, p<0.05, \eta_{\text {partial }}^{2}=0.06\right]$. Simple effects analyses revealed the following findings. Although net accuracy levels increased with age, we found that there was a significant difference between the net accuracy scores for the different emotional videos only for the 6-8 year-olds $\left[F(2,58)=4.03, p<0.05, \eta_{\text {partial }}^{2}=0.12\right]$. That is, for the younger children, neutral net accuracy scores were borderline significantly lower than the negative accuracy scores $(p=0.06)$. All other differences were not significant.

\section{DRM Paradigm}

\section{True Memory}

A 3 (age: 6-8 year-olds, 10-12 year-olds, adults) $\times 2$ (valence: negative vs. neutral) repeated-measures ANOVA was executed on the proportion of true recognition. The analyses showed a significant age $\times$ valence interaction $[F(2,87)=17.60$, $\left.p<0.001, \eta_{\text {partial }}^{2}=0.29\right]$. Extra simple effects showed that only for the negative true memories was there not a positive linear increase with age; that is, 10-12 year-olds and adults did not differ significantly with respect to true recognition levels for the negative word lists (see Table 2). For the neutral word lists, we did find that when getting older, true recognition levels increased linearly with age $\left[F(2,87)=40.24, p<0.001, \eta_{\text {partial }}^{2}=0.48\right]$. Also, simple effects showed that the younger and older children significantly recollected the negative words better than the neutral words (both $p$-values $<0.001$ ), while for the adults this difference was not significant $(p>0.05)$.

Table 2. Proportion of true recognition, false recognition, and net accuracy as a function of age and valence (SDs in parentheses)

\begin{tabular}{|c|c|c|c|c|c|c|}
\hline & \multicolumn{2}{|c|}{$6-8$ year-olds } & \multicolumn{2}{|c|}{$10-12$ year-olds } & \multicolumn{2}{|c|}{ Adults } \\
\hline & Neutral & Negative & Neutral & Negative & Neutral & Negative \\
\hline True recognition & $0.41(0.19)$ & $0.61(0.17)$ & $0.62(0.17)$ & $0.76(0.11)$ & $0.80(0.12)$ & $0.76(0.12)$ \\
\hline False recognition & $0.32(0.18)$ & $0.53(0.24)$ & $0.62(0.33)$ & $0.73(0.24)$ & $0.55(0.31)$ & $0.55(0.29)$ \\
\hline Net accuracy & $0.59(0.20)$ & $0.56(0.15)$ & $0.53(0.16)$ & $0.53(0.12)$ & $0.62(0.17)$ & $0.61(0.16)$ \\
\hline
\end{tabular}




\section{False Memory}

When we performed our analyses on the proportion of false recognition of the critical lures, our analyses showed a significant age $\times$ valence interaction $[F(2,87)=3.39$, $\left.p<0.05, \eta_{\text {partial }}^{2}=0.07\right]$. Simple effects showed that for both neutral and negative word lists, false memories increased significantly with age, with older children having significantly higher false memory rates than younger children $(p<0.05)$. The 10-12 year-olds and adults, however, did not differ in their propensity to false memories. Moreover, we found that for both child group values, negative false memories were more easily elicited than neutral false memories (both $p<0.05$ ), whereas for the adults, no significant differences emerged. An analysis of the related lures only showed a significant main effect of valence $[F(1,87)=14.31, p<0.001$, $\left.\eta_{\text {partial }}^{2}=0.14\right]$, with participants falsely assenting more to negative-related lures $(M=0.22, \mathrm{SD}=0.19)$ than to neutral-related lures $(M=0.13, \mathrm{SD}=0.19)$. For the unrelated items, we found a significant age effect $\left[F(2,87)=3.24, p<0.05, \eta_{\text {partial }}^{2}=0.07\right]$. Post hoc Bonferroni tests revealed that only the $6-8$ year-olds $(M=0.16, \mathrm{SD}=0.12)$ had marginally significantly higher unrelated scores than the adults $(M=0.09, \mathrm{SD}=0.08)$. All other effects did attain statistical significance $(p>0.05)$.

\section{Net Accuracy}

A repeated-measures ANOVA on the net accuracy scores did not detect a significant interaction $(F<1, p>0.05)$. A significant age effect did emerge $[F(2,87)=4.17$, $p<0.001, \eta_{\text {partial }}^{2}=0.09$ ], with the 10-12 year-olds having significantly lower net accuracy scores than the adults $(p<0.05)$. All other differences did not meet conventional levels of significance.

\section{Correlational Analysis}

Of particular interest was the assessment of whether different indexes of DRM false memories [critical lures, (un)related lures] were related to video false memories (critical items, unrelated items). Because we found developmental differences in false memory proneness for the DRM and video false memories, Pearson's correlations were computed between DRM and video false memories for each age group separately. Intriguingly, for each group, we found evidence that DRM illusions were related to false memories elicited by the video false memory task. That is, for the 6-8 year-olds $(r=0.41, p<0.05), 10-12$ year-olds $(r=0.39, p<0.05)$ and adults $(r=0.37, p<0.05)$, we found moderate to large positive correlations between the positive video false memory rates for the critical items and the DRM unrelated scores. Furthermore, for the 10-12 year-olds, a significant correlation was evident between the neutral video false memory rates for the critical items and neutral DRM-related rates $(r=0.49, p<0.01)$. Negative video false memory rates for the critical items were also significantly related to negative DRM critical $(r=0.37, p<0.05)$ and related lures $(r=0.43, p<0.05)$. Finally, for the adult sample, we found that neutral video false memory rates for the critical items were significantly related to DRM-unrelated words $(r=0.61, p<0.001)$. Moreover, our analysis revealed significant correlations between negative video false memory rates and negative DRM-related lures $(r=-0.39, p<0.05)$ and neutral DRM-related lures $(r=-0.38, p<0.05)$. 
A subsidiary aim was to examine correlations between true memories inferred from the video false memory paradigm and the DRM paradigm. For each group, we found indications that true memory levels in the video false memory paradigm were positively related to true memory levels in the DRM paradigm. For the $6-8$ year-olds $(r=0.49$, $p<0.01)$ and the $10-12$ year-olds $(r=0.60, p<0.001)$, we found positive correlations between negative video true memories and neutral DRM true memories. Furthermore, adults' neutral video true memories were positively related to adults' neutral DRM true memories $(r=0.44, p<0.05)$.

\section{DISCUSSION}

In the present study, we were interested in developmental trends of different types of spontaneous false memories. This interest was catalyzed by recent studies showing that children have lower spontaneous false memory levels than adults. This finding is called a developmental reversal effect and counters the default assumption in the legal and memory field stating that children are more susceptible to memory illusions than adults (Brainerd et al., 2008). The present study examined whether this novel developmental trend would also appear in another type of spontaneous false memory, namely, false memories that are elicited by a video memory paradigm. Furthermore, a secondary purpose was to test how different types of spontaneous false memory were related to each other and how emotional differences in stimulus material had an effect on false memory rates.

It is important to stress that our idea behind using videos to evoke spontaneous false memories was to include stimuli containing more obvious themes than simple DRM word lists. So, in a sense, our study examined differences between developmental trends of spontaneous false memories of stimuli with obvious (i.e., videos) and less obvious (i.e., DRM word lists) themes. Interestingly, we found that when using such a video false memory paradigm to elicit spontaneous false memories, both younger and older children had higher levels of spontaneous false memories than adults, yet had lower net accuracy scores than adults. Although this effect might seem to be in contrast to the literature on the developmental reversal effect, the effect is anticipated by false memory theories as AAT (Howe et al., 2009). According to AAT, developmental trends in spontaneous false memories might become attenuated or even reversed when stimuli contain obvious underlying themes. These themes can result in a rapid associative activation in one's knowledge base that is more advantageous for children whose associative activation processes are less well developed than adults. As a consequence, spontaneous false memory rates can become elevated in children and might even grow more extensively relative to adults' false memory rates.

This is exactly what we demonstrated in the present study. So, younger and older children evinced higher false memory rates than adults when they received videos with obvious themes of a street fight, birthday party, and an electrician. Furthermore, our findings fit perfectly with recent research showing that when stimuli with obvious themes are employed, age patterns in spontaneous false memories weaken or reverse (Howe \& Wilkinson, 2011; Otgaar, Howe, et al., 2012; Swannell \& Dewhurst, in press). These studies show that stimuli such as story contexts and scene-like pictures are also capable of modifying developmental trends in spontaneous false memories. Our study provides additional proof that themes might play a significant role in the 
formation of false memories and that such themes can be readily identified in stimuli such as pictures (Otgaar et al., 2012) and videos.

Furthermore, recent studies are increasingly using other paradigms to evoke spontaneous false memories, with the intention of understanding the precise mechanisms and broadening the robustness of these false memories (e.g., Lyons, Ghetti, \& Cornoldi, 2010; Mirandola, Paparella, Ghetti, \& Cornoldi, in press). For example, Mirandola et al. provided children with or without symptoms of attention deficit hyperactivity disorder with photographs depicting different scripts (e.g., eating in a restaurant). During a recognition task, script-consistent yet false information was incorporated. Their results showed that this paradigm was effective in eliciting spontaneous false memories in these children. Our video false memory paradigm falls nicely in this new research line of using different spontaneous false memory paradigms.

We also found that when using the DRM paradigm, the standard developmental reversal effect occurred, with the older children and adults being more likely to produce false memories than the younger children (Brainerd et al., 2008). As mentioned earlier, this effect is probably driven by either increased gist processing (FTT) or faster and more automatic associative activation (AAT) of adults relative to children. In both the video and DRM false memory paradigms, we also replicated the result that true memories increased significantly with age (see Brainerd et al., 2008; Otgaar, Howe, et al., 2012). However, only in the DRM paradigm was this increase in true memory paralleled by an increase in false memory with age (Howe et al., 2009).

Our experiment also provided tentative data showing that on a general level, different types of spontaneous false memory are related to each other. That is, we found for all ages that several DRM indexes of false memory [critical lures, (un)related] were positively related to indexes of spontaneous video false memories (but see some exceptions with adult data). These data suggest that, despite opposing developmental trends, different types of spontaneous false memories share a common mechanism. This is corroborated by our finding that video true memories were positively related to DRM true memories. There are even data showing that DRM false memories are positively related to suggestion-based false memories (Otgaar et al., 2012; Qin et al., 2008), a result that is in accordance with the tenets of AAT.

We also examined false memory differences with respect to varying emotional stimuli. For the DRM paradigm, we replicated earlier findings (e.g., Howe et al., 2010) showing that false recognition was higher for negative than for neutral material albeit not for adults who did not differ in false recognition for negative and neutral material. Our result that negative word lists were more likely to give rise to false memories than neutral word lists may be the result of people being better able to extract the gist from negative experiences (FTT - Brainerd et al., 2008) or because negative memories are stored in better integrated, semantically denser (hence more readily and automatically activated) associative networks (AAT - Howe et al., 2010; see also Talmi \& Moscovitch, 2004). So, based on AAT, spreading activation is more likely to distribute faster through negative recollections, thereby increasing the probability of developing memory illusions.

However, we did not find that negative false memories were more easily induced than other false memories (neutral, positive) in the video false memory paradigm. On the contrary, both children and adults were less likely to form negative false memories than neutral or positive false memories. How can we explain this finding? It is true that studies have found mixed results with respect to the effect of emotion on false memory 
rates, with some studies showing enhanced neutral false recall relative to negative false recall (e.g., Otgaar, Peters and Howe, 2012) and other studies demonstrating increased negative false recognition relative to neutral false recognition (Howe et al., 2010). However, in our video false memory paradigm, we used a recognition task to measure false memories, so one would expect negative false memories to be more easily elicited than neutral or positive false memories.

In our opinion, there are two explanations that might have merit in this regard. First, there are studies showing that people are not likely to err when they are presented with unpleasant and negative material that might stimulate embarrassing feelings (Bruck \& Ceci, 1999; Saywitz, Goodman, Nicholas, \& Moan, 1991; Schaaf, Alexander, \& Goodman, 2008). Secondly and relatedly, it is possible that our negative video about the street fight was much more distinctive than the other videos, thereby increasing item-specific processing. Research shows that distinctive experiences reduce false memory rates (Hege \& Dudson, 2004), because items are better discriminated between each other, thereby lowering chances that people falsely recognize items. Future studies therefore should consider mapping the videos on dimensions such as distinctiveness.

Our findings are relevant for the legal field; that is, a vast amount of studies have shown that children are more likely to produce tainted memory reports than adults (Ceci \& Bruck, 1993) and that, other things being equal, children's memories are less reliable than adults' memories when suggestive manipulations are at work. The ultimate consequence of this finding is that, to date, legal professionals (police, lawyers, judges, etc.) operate under the assumption that in legal cases in which there is a memory report of a child and an adult, adults' statements are more likely to be trusted than children's (Brainerd et al., 2008). Furthermore, this finding has led to the development of specific interview protocols for children, ones that stimulate the reporting of true information, but reduce the possibility of errant reports (e.g., Lamb, Hershokowitz, Orbach, \& Esplin, 2008).

However, consistent with the current experiment, recent studies have shown that this view concerning the nature of developmental trends in false memory is untenable (e.g., Otgaar, Howe, et al., 2012). These studies show that spontaneous false memories show the opposite developmental pattern. Importantly, this developmental pattern has been predicted by theories such as FTT and AAT. There are even studies showing that under certain situations suggestion-based false memories increase with age (Otgaar, Howe, et al., 2012). To be clear, AAT posits that suggestibility effects that mainly develop because of social influences will follow an age-related decrease in false memories, whereas suggestion-based false memories that arise as a result of actual memory aberrations will show an age-related increase in false memories. The consequence of these studies and the current study is that it is likely that we need to adopt a more balanced view about the reliability of children's and adults' memory.

Based on this research, we think it is imperative that researchers and legal professionals alike be cognizant of the circumstances under which false memories increase or decrease with age. Since spontaneous false memories are likely to occur in legal cases (Holliday, Reyna, \& Brainerd, 2008), it is crucial to understand which manipulations might foster or decrease the development of false memories, especially those that may occur in interrogation settings. Based on FTT and AAT, one could predict that questions that stimulate verbatim memory ("What kind of knife was present?") would reduce false memories, while questions that lead to more thematic processing or spreading activation ("Which weapon was at the crime scene?") would increase false memories (Pansky \& Tenenboim, 2011). 
Taken together, although our study has revealed different developmental trajectories for different types of spontaneous false memories, these opposing trends were well articulated by the assumptions of theme nodes of AAT. Specifically, we predicted that, with the help of obvious themes, developmental patterns in spontaneous false memories can attenuate or reverse. Our findings can elucidate which mechanisms underlie the development of false memories, yet are also relevant for practical issues. In the end, unraveling practical questions such as the reliability of testimonies will only succeed when these questions are grounded in sound theory.

\section{ACKNOWLEDGMENTS}

Contributions from H.O. were supported by a grant from the Netherlands Organization for Scientific Research (NWO; 016.135.052 and by a grant from the Edmund Hustinx Foundation). M.L.H. was supported by a grant (RES-062-23-3327) from the Economic and Social Research Council, UK.

\section{REFERENCES}

Baayen, R. H., Piepenbrock, R., \& Gulikers, L. (1995). The CELEX lexical database [CD-ROM]. Philadelphia: University of Pennsylvania.

Brainerd, C. J., Holliday, R. E., Reyna, V. F., Yang, Y., \& Toglia, M. P. (2010). Developmental reversals in false memory: Effects of emotional valence and arousal. Fournal of Experimental Child Psychology, 107, $137-154$.

Brainerd, C. J., Reyna, V. F., \& Ceci, S. J. (2008). Developmental reversals in false memory: A review of data and theory. Psychological Bulletin, 134, 343-382.

Bruck, M., \& Ceci, S. J. (1999). The suggestibility of children's memory. Annual Review of Psychology, 50, 419-439.

Ceci, S. J., \& Bruck, M. (1993). Suggestibility of the child witness: A historical review and synthesis. Psychological Bulletin, 113, 403-439.

Ceci, S. J., \& Huffman, M. L. C. (1997). How suggestible are preschool children? Cognitive and social factors. Fournal of the American Academy of Child and Adolescent Psychiatry, 36, 948-958.

Clancy, S. A., McNally, R. J., Schachter, D. L., Lenzenweger, M., \& Pitman, R. K. (2002). Memory distortion in people reporting abduction by aliens. Fournal of Abnormal Psychology, 111, 455-461.

Deese, J. (1959). On the prediction of occurrence of particular verbal intrusions in immediate recall. fournal of Experimental Psychology, 58, 17-22.

DePrince, A. P., Allard, C. B., Oh, H., \& Freyd, J. J. (2004). What's in a name for memory errors? Implications and ethical issues arising from the use of the term "false memory" for errors in memory for details. Ethics $\mathcal{E}$ Behavior, 14, 201-233.

Dewhurst, S. A., Pursglove, R. C., \& Lewis, C. (2007). Story contexts increase susceptibility to the DRM illusion in 5-year-olds. Developmental Science, 10, 374-378.

Gallo, D. A. (2010). False memories and fantastic beliefs: 15 years of the DRM illusion. Memory E Cognition, 38, 833-848.

Geraerts, E., Lindsay, D. S., Merckelbach, H., Jelicic, M., Raymaekers, L., Arnold, M. M., \& Schooler, J. S. (2009). Cognitive mechanisms underlying recovered memory experiences of childhood sexual abuse. Psychological Science, 20, 92-98.

Goodman, G. S., Ogle, C. M., Block, S. D., Harris, L. S., Larson, R. P., Augusti, E., ... Urquiza, A. (2011). False memory for trauma-related Deese-Roediger-McDermott lists in adolescents and adults with histories of child sexual abuse. Development and Psychopathology, 23, 423-438.

Hege, C. G., \& Dudson, C. S. (2004). Why distinctive information reduces false memories: Evidence for both impoverished relational-encoding and distinctiveness heuristic accounts. Fournal of Experimental Psychology: Learning, Memory, and Cognition, 30, 787-795.

Holliday, R. E., Reyna, V. F., \& Brainerd, C. J. (2008). Recall of details never experienced: Effects of age, repetition, and semantic cues. Cognitive Development, 23, 67-78.

Howe, M. L., \& Wilkinson, S. (2011). Using story contexts to bias children's true and false memories. Fournal of Experimental Child Psychology, 108, 77-95. 
Howe, M. L., Candel, I., Otgaar, H., Malone, C., \& Wimmer, M. C. (2010). The role of valence in the development of immediate and long-term false memory illusions. Memory, 18, 58-75.

Howe, M. L., Wimmer, M. C., Gagnon, N., \& Plumpton, S. (2009). An associative-activation theory of children's and adults' memory illusions. Fournal of Memory and Language, 60, 229-251.

Johnson, M. K., Hashtroudi, S., \& Lindsay, D. S. (1993). Source monitoring. Psychological Bulletin, 114, 3-28.

Lamb, M., Hershokowitz, I., Orbach, Y., \& Esplin, P. (2008). Tell Me What Happened: Structured Investigative Interviews of Child Victims and Witnesses. England: John Wiley \& Sons.

Lindsay, D. S., Johnson, M. K., \& Kwon, P. (1991). Developmental changes in memory source monitoring. fournal of Experimental Child Psychology, 52, 297-318.

Loftus, E. F. (2005). Planting misinformation in the human mind: A 30-year investigation of the malleability of memory. Learning \& Memory, 12, 361-366.

Loftus, E. F., \& Pickrell, J. E. (1995). The formation of false memories. Psychiatric Annals, 25, 720-725.

Lyons, K. E., Ghetti, S., \& Cornoldi, C. (2010). Age differences in the contribution of recollection and familiarity to false-memory formation: A new paradigm to examine developmental reversal. Developmental Science, 13, 335-362.

Meyersburg, C. A., Bogdan, R., Gallo, D. A., \& McNally, R. J. (2009). False memory propensity in people reporting recovered memories of past lives. Fournal of Abnormal Psychology, 118, 399-404.

Mirandola, C., Paparella, G., Ghetti, S., \& Cornoldi, C. (2012). Children with ADHD symptoms are less susceptible to gap-filling errors than typically developing children. Learning and Individual Differences, 22, 896-900.

Otgaar, H., \& Candel, I. (2011). Children's false memories: Different false memory paradigms reveal different results. Psychology, Crime $\mathcal{E}$ Law, 17, 513-528.

Otgaar, H., Candel, I., Scoboria, A., \& Merckelbach, H. (2010). Script knowledge enhances the development of children's false memories. Acta Psychologica, 133, 57-63.

Otgaar, H., Candel, I., Smeets, T., \& Merckelbach, H. (2010). "You didn't take Lucy's skirt off”: The effect of misleading information on omissions and commissions in children's memory reports. Legal and Criminological Psychology, 15, 229-241.

Otgaar, H., Howe, M. L., Peters, M., Smeets, T., \& Moritz, S. (2012). The rise of memory illusions in childhood: An associative-activation account. Manuscript submitted for publication.

Otgaar, H., Peters, M. J. V., \& Howe, M. L. (2012). Dividing attention lowers children's, but increases adults' false memories. Fournal of Experimental Psychology. Learning, Memory, and Cognition, 38, $204-210$.

Otgaar, H., \& Smeets, T. (2010). Adaptive memory: Survival processing increases both true and false memory in adults and children. Fournal of Experimental Psychology: Learning, Memory, and Cognition, 36, 1010-1016.

Otgaar, H., Candel, I., \& Merckelbach, H. (2008). Children's false memories: Easier to elicit for a negative than for a neutral event. Acta Psychologica, 128, 350-354.

Otgaar, H., Candel, I., Merckelbach, H., \& Wade, K. A. (2009). Abducted by a UFO: Prevalence information affects young children's false memories for an implausible event. Applied Cognitive Psychology, 23, 115-125.

Otgaar, H., Verschuere, B., Meijer, E. H., \& van Oorsouw, K. (2012). The origin of children's implanted false memories: Memory traces or compliance. Acta Psychologica, 139, 397-403.

Pansky, A., \& Tenenboim, E. (2011). Inoculating against eyewitness suggestibility via interpolated verbatim vs. gist testing. Memory $\mathcal{E}$ Cognition, 39, 155-170.

Peters, M. J. V., Hauschildt, M., Moritz, S., \& Jelinek, L. (2012). Impact of emotionality on memory and meta-memory in schizophrenia using video sequences. Fournal of Behavior Therapy and Experimental Psychiatry, 44, 77-83.

Pezdek, K., \& Lam, S. (2007). What research paradigms have cognitive psychologists used to study "False memory", and what are the implications of these choices? Consciousness and Cognition, 16, 2-17.

Pezdek, K., \& Roe, C. (1997). The suggestibility of children's memory for being touched: Planting, erasing, and changing memories. Law and Human Behavior, 21, 95-106.

Porter, S., Taylor, K., \& ten Brinke, L. (2008). Memory for media: Investigation for negatively and positively charged public events. Memory, 16, 658-666.

Pratte, M. S., \& Rouder, J. N. (2011). Hierarchical single- and dual-process models of recognition memory. Fournal of Mathematical Psychology, 55, 36-46.

Qin, J., Ogle, C. M., \& Goodman, G. S. (2008). Adults' memories of childhood: True and false reports. Fournal of Experimental Psychology. Applied, 14, 373-391.

Reyna, V. F., \& Brainerd, C. J. (2011). Dual processes in decision making and developmental neuroscience: A fuzzy-trace model. Developmental Review, 31, 180-206.

Roediger, H. L., \& McDermott, K. (1995). Creating false memories: Remembering words not presented in a list. Fournal of Experimental Psychology: Learning, Memory, and Cognition, 21, 803-814.

Rubin, D. C., \& Talarico, J. M. (2009). A comparison of dimensional models of emotion: Evidence from emotions, prototypical events, autobiographical memories, and words. Memory, 8, 802-808.

Saywitz, K. J., Goodman, G. S., Nicholas, E., \& Moan, S. F. (1991). Children's memories of a physical examination involving genital touch: implications for reports of child sexual abuse. Fournal of Consulting and Clinical Psychology, 59, 682-691.

Schaaf, J. M., Alexander, K. W., \& Goodman, G. S. (2008). Children's false memory and true disclosure in the face of repeated questions. Fournal of Experimental Child Psychology, 100, 157-185. 
Sutherland, R., \& Hayne, H. (2001). Age-related changes in the misinformation effect. Fournal of Experimental Child Psychology, 79, 388-404.

Swannell, E. R., \& Dewhurst, S. A. (2013). Effects of presentation format and list length on children's false memories. Fournal of Cognition and Development, 14, 332-342.

Talmi, D., \& Moscovitch, M. (2004). Can semantic relatedness explain the enhancement of memory for emotional words? Memory E Cognition, 32, 742-751.

Van Loon-Vervoorn, W. A., \& Van Bekkum, I. J. (1991). Woordassociatie lexicon. [Word association lexicon]. Amsterdam, the Netherlands: Swets \& Zeitlinger.

Wade, K., Sharman, S., Garry, M., Memon, A., Mazzoni, G., Merckelbach, H., \& Loftus, E. (2007). False claims about false memory research. Consciousness and Cognition, 16, 18-28.

Wilkinson, C., \& Hyman, I. E. (1998). Individual differences related to two types of memory errors: Word lists may not generalize to autobiographical memory. Applied Cognitive Psychology, 12, S29-S46. 